\title{
Evaluation of the Characteristics of the Control Valves
}

\author{
Jana Jablonská1,* , and Milada Kozubková ${ }^{1}$ \\ ${ }^{1}$ VSB - Technical University of Ostrava, Faculty of Mechanical Engineering, Department of \\ Hydromechanics and Hydraulic Equipment, 17. listopadu 2172/15, 70800 Ostrava-Poruba, Czech \\ Republic
}

\begin{abstract}
When designing pipeline networks, the knowledge of loss coefficient respectively resistance coefficient when flowing through various types of fluids through hydraulic elements, e.g. control valves, which are often used in the engineering and energy industry. Their specification is performed mainly experimentally. However, there are applications where the experimental approach of their determination is unrealistic and then mathematical methods can be considered. The article presents a methodology for determining the static characteristics of the DN25 control valve for different opening. The measurement of the characteristics was performed with an incompressible flowing medium - water and with a compressible flowing medium - air. Subsequently, a comparison of measurement and evaluation of loss and flow coefficients was performed. The measured values will be further used to verify the results of modelling and to precisely define mathematical models, so that the models can be subsequently used at vapour flow, where the experimental method of determination is difficult. Frequent applications are found in the flow of saturated and superheated vapour through control valves.
\end{abstract}

\section{Introduction to the issue}

The aim of this work is to create a methodology for measuring the flux through the valve, during the flow of incompressible medium (water) and compressible medium (air, vapour). To evaluate the resistance coefficients, it is appropriate to define the type of flow using dimensionless parameters. The criterion for determining the type of flow is the Reynolds number $(R e)$ :

$$
R e=\frac{v \cdot d}{v}
$$

where $v$ is the mean velocity, $d$ is the characteristic dimension and $v$ is the kinematic viscosity. For the transition of laminar flow to turbulent flow, the limit resp. critical Reynolds number for control valves is specified, $R e_{c r i t}=4000$ [2]. If the Reynolds number is greater than the $R e_{\text {crit }}$, it is a turbulent flow. If the Reynolds number is less than $R e_{\text {crit }}$, it is a laminar flow. In most practical applications, this is a developed turbulent flow, which means that the loss coefficient no longer changes with the size of the Reynolds number. The influence

\footnotetext{
* Corresponding author: jana.jablonska@vsb.cz
} 
of the Reynolds number on the flow behaviour is manifested at low flow through the control valve with a small flow coefficient, at high viscosities and at a small pressure drop. The cavitation number determines the level of cavitation development. The cavitation number for the valves is defined

$$
C a=\frac{p_{1}-p_{w}}{p_{1}-p_{2}}
$$

where $p_{1}$ is the pressure in front of the valve, $p_{2}$ is the pressure behind the valve, $p_{w}$ is the pressure of saturated water vapour. In general, cavitation does not occur at high cavitation number. The higher values of the cavitation number correspond to the higher values of the measured pressure, i.e. the measured pressure will usually be higher than the saturated vapour pressure [8].

The static characteristic of the valve determines the dependence of the pressure difference $\Delta p$ on the volume flow rate $Q$ according to basic Bernoulli's equation

$$
\Delta p=\xi \cdot \rho \cdot \frac{v^{2}}{2}=\frac{\xi \cdot \rho}{2 \cdot S^{2}} \cdot Q^{2}
$$

There is a general dependence for turbulent flow

$$
\Delta p=R \cdot Q_{v}^{2}
$$

Comparing equations (3) and (4) gives the relationship between the loss coefficient $\xi$ and the resistance to motion $R$

$$
\xi=\frac{R \cdot 2 \cdot S^{2}}{\rho}
$$

The valves are also often mentioned discharge coefficient $\mu$ which is determined

$$
\mu=\frac{1}{\sqrt{\xi}}
$$

In technical practice, flow coefficients are defined in the manufacturers catalogue. The magnitude of this coefficient indicates the characteristic flow rate through a given valve under precisely defined conditions at $100 \%$ stroke. The higher this coefficient, the higher amount can flow through the element or system. The flow coefficient, called $A v$, is directly dependent on the volume or mass flow rate and the square root of the pressure loss. It can be determined from the equation

$$
A_{v}=S \cdot \sqrt{\frac{2}{\xi}}=Q \cdot \sqrt{\frac{\rho}{\Delta p}}
$$

This equation also gives the basic conversion relationship between the loss coefficient $\xi$ and the flow coefficient $A v$. At present, the flow coefficient called $K v$, which is defined, is almost exclusively used

$$
K_{v}=\frac{1}{100} \cdot Q \cdot \sqrt{\frac{\rho}{\Delta p}}
$$

where $Q$ is the volume flow rate $\left[\mathrm{m}^{3} \cdot \mathrm{h}^{-1}\right], \rho$ is the density in $\left[\mathrm{kg} \cdot \mathrm{m}^{-3}\right]$ and $\Delta p$ is the pressure drop in [MPa]. Table 1 provides simplified formulas for incompressible and compressible fluid flows $[2,9]$.

A subcritical pressure drop occurs when the outlet velocity from the control volume does not exceed the velocity of sound, a supercritical pressure drop occurs when the outlet velocity from the control volume is higher than the velocity of sound. It is clear from the measurements that the solved flow area is a subcritical area.

The flow coefficient, referred to as $C v$, is used worldwide, especially in countries where a SI system of units is not in place. It is equivalent to the $K v$ or $A v$ value and expresses the amount of US gallons of water at temperature $40-100^{\circ} \mathrm{F}$ that flows through the valve in 1 minute at a pressure drop of 1 psi ( 1 US gallon $=3.7854$ litters, $1 \mathrm{psi}=6894.8 \mathrm{~Pa}$ ) [2]. 
Table 1. Simplified formulas for the flow rate of incompressible and compressed fluids through a valve $[1,2]$.

\begin{tabular}{|l|c|c|}
\hline & $\begin{array}{c}\text { subcritical pressure drop } \\
\Delta p<\frac{p_{1}}{2}\end{array}$ & $\begin{array}{c}\text { supercritical pressure drop } \\
\Delta p \geq \frac{p_{1}}{2}\end{array}$ \\
\hline incompressible fluid (water) & $K_{v}=\frac{1}{100} \cdot Q \cdot \sqrt{\frac{\rho}{\Delta p}}$ & $K_{v}=\frac{1}{100} \cdot Q \cdot \sqrt{\frac{\rho}{\Delta p}}$ \\
\hline gas (air) & $K_{v}=\frac{\mathrm{Q}_{n}}{5141} \cdot \sqrt{\frac{\rho_{n} \cdot T_{1}}{\Delta p \cdot p_{2}}}$ & $K_{v}=\frac{2 \cdot \mathrm{Q}_{n}}{5141 \cdot p_{1}} \cdot \sqrt{\rho_{n} \cdot T_{1}}$ \\
\hline superheated vapour & $K_{v}=\frac{\mathrm{Q}_{m}}{100} \cdot \sqrt{\frac{v_{2}}{\Delta p}}$ & $K_{v}=\frac{\mathrm{Q}_{m}}{100} \cdot \sqrt{\frac{2 \cdot v_{1}}{p_{1}}}$ \\
\hline saturated and wet vapour & $K_{v}=\frac{\mathrm{Q}_{m}}{100} \cdot \sqrt{\frac{v_{2} \cdot \mathrm{x}}{\Delta p}}$ & $K_{v}=\frac{\mathrm{Q}_{m}}{100} \cdot \sqrt{\frac{2 \cdot v_{1} \cdot x}{p_{1}}}$ \\
\hline
\end{tabular}

$p_{1}$ is the absolute pressure upstream of the control valve [MPa], $p_{2}$ is the absolute pressure downstream of the control valve [MPa], $\Delta p$ is the pressure drop across the valve [MPa], $Q_{n}$ is the normal volume flow rate $\left[\mathrm{m}^{3} \cdot \mathrm{h}^{-1}\right], Q_{m}$ is the mass flow rate at operating condition $p_{l}$, $T_{l}\left[\mathrm{~kg} \cdot \mathrm{h}^{-1}\right], T_{l}$ is the absolute temperature at the inlet to the valve $[\mathrm{K}], v_{l}$ is the specific volume of vapour at temperature $T_{1}$ and pressure $p_{I} / 2\left[\mathrm{~m}^{3} \cdot \mathrm{kg}^{-1}\right], v_{2}$ is the specific volume of vapour at temperature $T_{1}$ and pressure $p_{2}\left[\mathrm{~m}^{3} \cdot \mathrm{kg}^{-1}\right], x$ is the relative mass fraction of saturated vapour in wet vapour [1], $\rho_{n}$ is the density of the gas under normal conditions $\left[\mathrm{kg} \cdot \mathrm{m}^{-3}\right][2]$.

\section{Physical properties}

Two media were used in the experiment - water and air because of the simple, fast measurement. The basic physical properties for water, air and vapour at different temperatures and atmospheric pressure are given in Table 2. The physical properties of vapour depend significantly on the pressure, temperature and condition of the vapour.

Table 2. Table of physical properties for water, air and vapour at atmospheric pressure $[6,7,10]$.

\begin{tabular}{|c|c|c|c|c|}
\hline & & \multicolumn{3}{|c|}{ temperature } \\
\hline & & $20^{\circ} \mathrm{C}$ & $60^{\circ} \mathrm{C}$ & $100^{\circ} \mathrm{C}$ \\
\hline \multirow{3}{*}{ density $\left[\mathrm{kg} \cdot \mathrm{m}^{-3}\right]$} & water & 998.2 & 983.2 & 958.3 \\
\hline & air & 1.188 & 1.046 & 0.934 \\
\hline & vapour & - & - & 0.591 \\
\hline \multirow{3}{*}{$\begin{array}{c}\text { kinematic viscosity } \\
{\left[\mathrm{m}^{2} \cdot \mathrm{s}^{-1}\right]}\end{array}$} & water & $1.006 \cdot 10^{-6}$ & $0.478 \cdot 10^{-6}$ & $0.294 \cdot 10^{-6}$ \\
\hline & air & $15.32 \cdot 10^{-6}$ & $19.22 \cdot 10^{-6}$ & $2.33 \cdot 10^{-5}$ \\
\hline & vapour & - & - & $1.49 \cdot 10^{-5}$ \\
\hline
\end{tabular}

Figure 1 shows the dependence of the density and dynamic viscosity on temperature for water, air and vapour. It is evident from the graph that the density of air and vapour varies in 
units $\left[\mathrm{kg} \cdot \mathrm{m}^{-3}\right]$, the density of water varies in thousands $\left[\mathrm{kg} \cdot \mathrm{m}^{-3}\right]$. The density of the saturated vapour is marked by only one point, i.e. for atmospheric pressure.

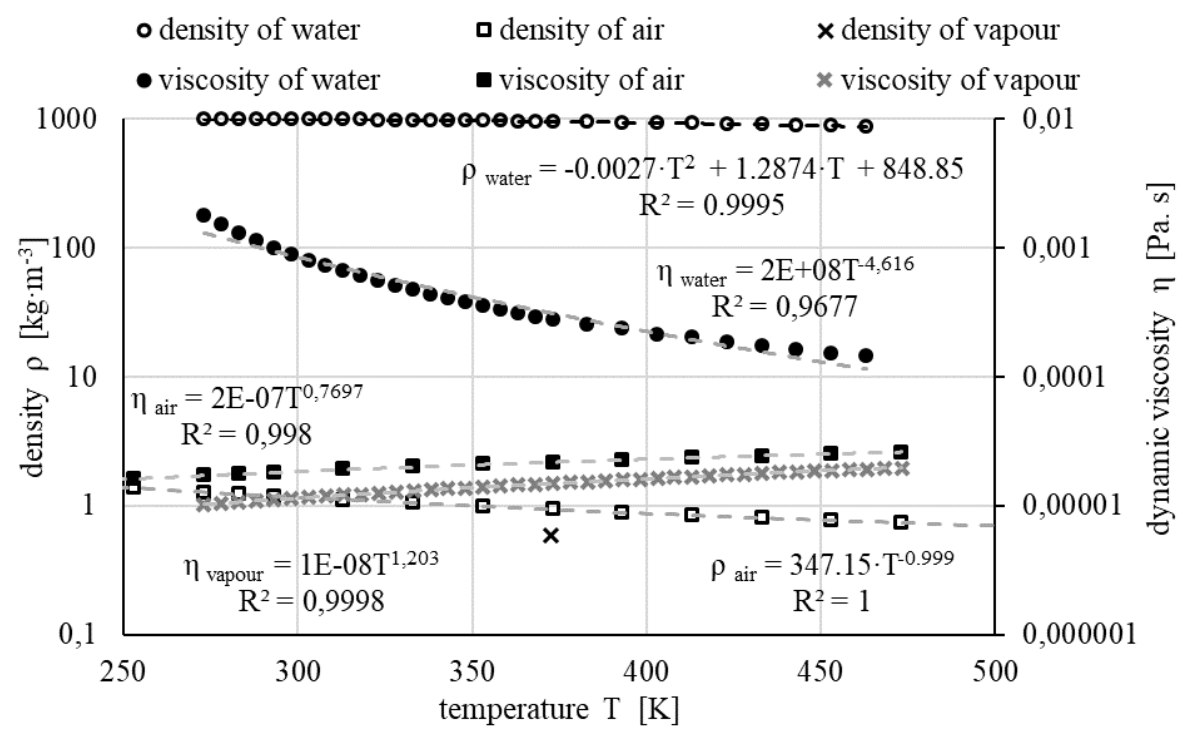

Fig. 1. Dependence of density and dynamic viscosity vs. temperature at atmospheric pressure. $[6,7$, 10]

The viscosity of air and vapour are very similar and it is based on Sutherland's law, which describes the relationship between the dynamic viscosity and the absolute temperature $T$ of an ideal gas. Sutherland's law is based on the idealized potential of intermolecular forces and the kinetic theory of ideal gases. This formula is still commonly used and provides relatively accurate results with an error of less than a few percent over a wide temperature range. Sutherland's law can be expressed as follows [10]

$$
\eta=\eta_{\text {ref }} \cdot\left(\frac{T}{T_{r e f}}\right)^{3 / 2} \cdot \frac{T_{r e f}+S}{T+S}
$$

Where $T_{r e f}$ is a reference temperature, $\eta_{r e f}$ is dynamic viscosity at the $T_{r e f}$ reference temperature, $S$ is the Sutherland temperature. For air, the constants are defined by $\eta_{r e f}=1.72 \cdot 10^{-5} \mathrm{~Pa} \cdot \mathrm{s}, T_{r e f}=273.11 \mathrm{~K}, S=110.56 \mathrm{~K}$. For vapour, the constants are defined by $\eta_{\text {ref }}=1.7 \cdot 10^{-5} \mathrm{~Pa} \cdot \mathrm{s}, T_{\text {ref }}=416.67 \mathrm{~K}, S=861.11 \mathrm{~K}[11]$.

Saturated vapour pressure increases with temperature. For water at temperature $293.15 \mathrm{~K}$ a saturated vapour pressure of $2300 \mathrm{~Pa}$ is given [5]. Saturated vapour pressure is the highest pressure at which a substance can exist in an equilibrium gaseous state at a given temperature. As the temperature of the liquid increases, the density and pressure of its saturated vapour increase.

\section{Description of the measuring device}

The circuits for measuring the characteristics of valves on the air line and water line were assembled and implemented at the department according to the standard ČSN EN 1267 "Industrial valves - Measurement of flow losses using water as a test fluid" [4], which prescribes requirements for testing of industrial valves. The measurement was performed according to the standard ČSN EN 60534-2-3 "Control valves for industrial processes - Part 
2-3: Flow rate - Test procedures" [3], which defines the distance of the location of the pressure taps in front of and behind the valve and the length of the pipe to stabilize the flow.

The measured valve of size DN 25 is from Armatury Group a.s. The stroke of the valve is adjusted by turning the wheel and the position is determined according to the gauge (see Figure 2). By turning to the correct position, full valve opening, $3 / 4$ opening, $1 / 2$ opening and $1 / 4$ opening can be set.

The measuring circuit for air and water was very similar. Figure 2 schematically shows a hydraulic circuit for testing the static characteristics of valves. Water, resp. air is sucked in by the pump, resp. by the fan (2) via a flow meter (3) to the measured element - valve (4). Pump velocity resp. fan is controlled by a frequency converter. The pressure sensors (5) are located in front of and behind the valve according to the standard [4], both measured pressures are recorded in the evaluation device (6). The water circuit continues to go below the surface into the tank (1). The sensor of temperature is disposed in the water tank for evaluation of temperature $\left(23.2^{\circ} \mathrm{C}\right)$, and air temperature was $23^{\circ} \mathrm{C}$.
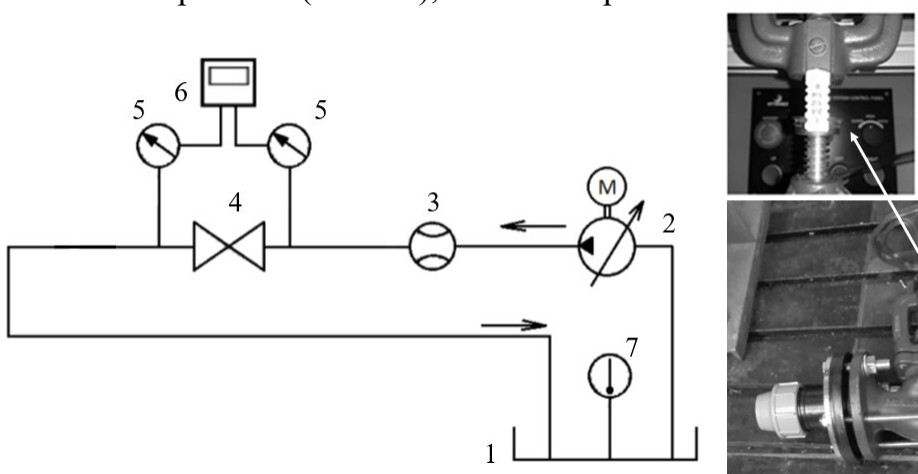

Fig. 2. Water circuit diagram - 1 tank, 2 pump, 3 flow meter, 4 measured element - valve, 5 pressure sensor, 6 evaluation device, 7 thermometer.

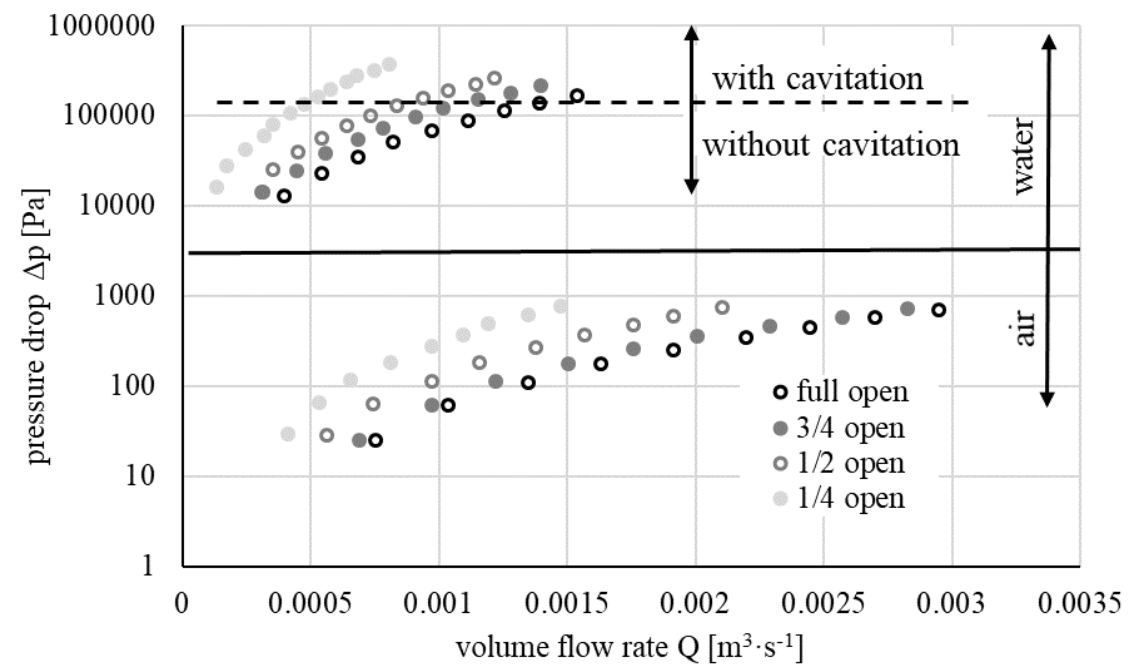

Fig. 3. Dependence of pressure drop vs. volume flow rate. 


\section{Evaluation of measurement of hydraulic parameters}

The most important characteristic of the valve, determined by measurement according to the relevant standards, is the flow characteristic, i.e. the dependence of the pressure drop on the volume flow rate: $\Delta p=\mathrm{f}(Q)$, see Figure 3. The volume flow range was approximately the same for both fluids. On the water circuit, the values of the measured volume flow rate are in the range from $1.38 \cdot 10^{-4} \mathrm{~m}^{3} \cdot \mathrm{s}^{-1}$ to $1.54 \cdot 10^{-4} \mathrm{~m}^{3} \cdot \mathrm{s}^{-1}$, for the air circuit the values are from $4.15 \cdot 10^{-4} \mathrm{~m}^{3} \cdot \mathrm{s}^{-1}$ to $2.95 \cdot 10^{-4} \mathrm{~m}^{3} \cdot \mathrm{s}^{-1}$. The solid line divides the measured values for water and air. In both cases, equation (3) applies - with increasing pressure drop, the flow increases quadratically. Cavitation was created during the flow and in the graph the area with and without cavitation is divided by a dashed line.

Figure 4 shows the dependence of the flow coefficient $K v$ on the Reynolds number. The graph shows that the flow is mainly turbulent. The Reynolds number at the valve inlet for water is from 8807 to 98149 , for air from 1723 to 12272 . The dotted line shows the critical Reynolds number, which is reported as 4000 for flow through valve. The solid line divides measurements the water and air circuit. The flow coefficient depends on the physical properties of the flowing fluid (water, air). The dashed line divides the area with and without cavitation.

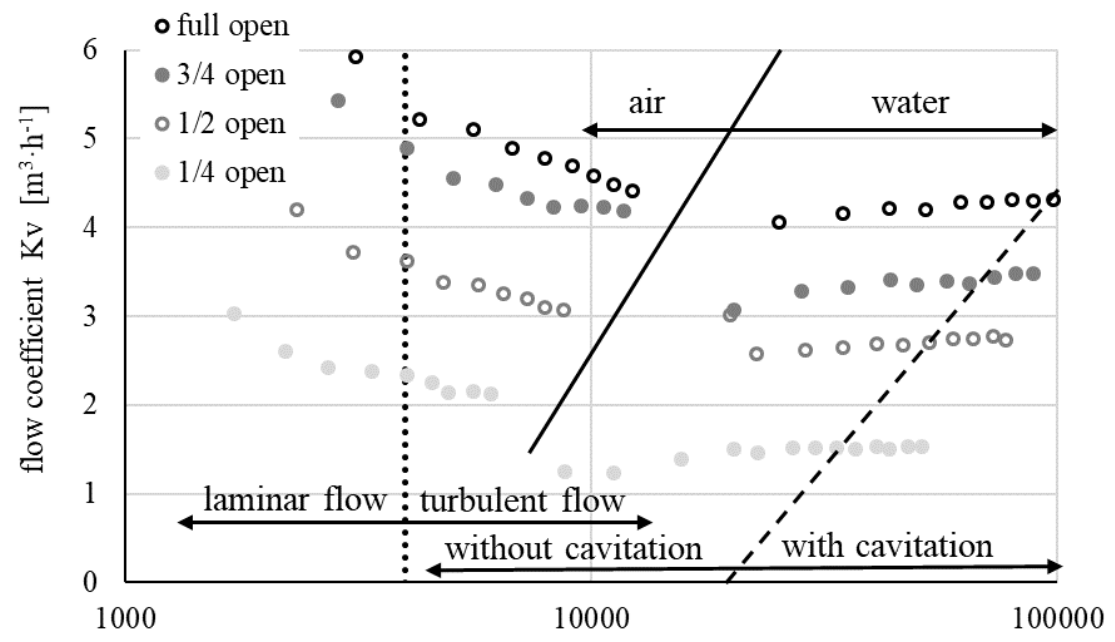

Reynolds number Re [1]

Fig. 4. Dependence of flow coefficient vs. Reynolds number.
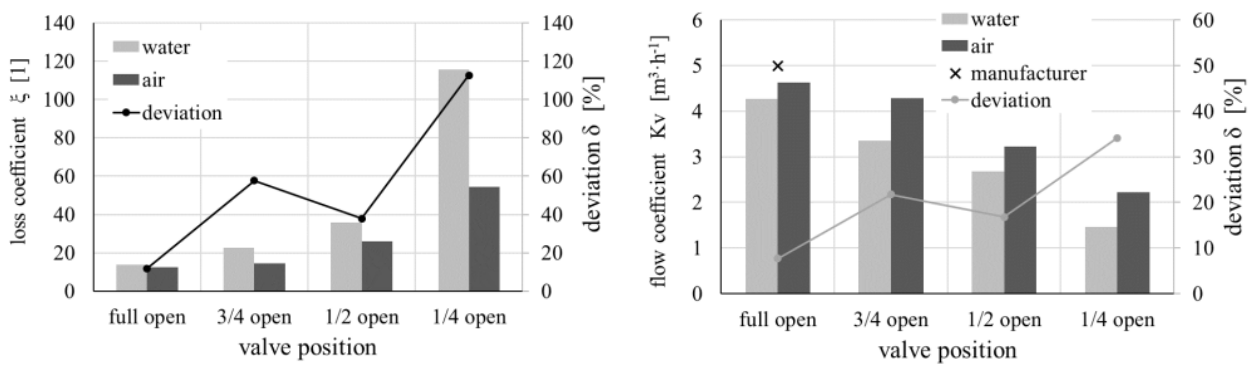

Fig. 5. Dependence of loss coefficient and flow coefficient vs valve position.

According to equation (5), a graph was created and the resistance to motion $\mathrm{R}$ was determined, which was subsequently converted according to equation (6) to the loss coefficient $\xi$. Figure 5 compares the loss coefficients as a function of the opening valve for 
the water and air. It can be seen from the graph that when closing the valve, the loss coefficient for water increases more significantly than for air. With the valve open, the water loss coefficient is $11.5 \%$ higher than the air loss coefficient.

Dependence of the cavitation number on the Reynolds number (water circuit) is evaluated and the critical cavitation number is 1.62 , see Figure 6.

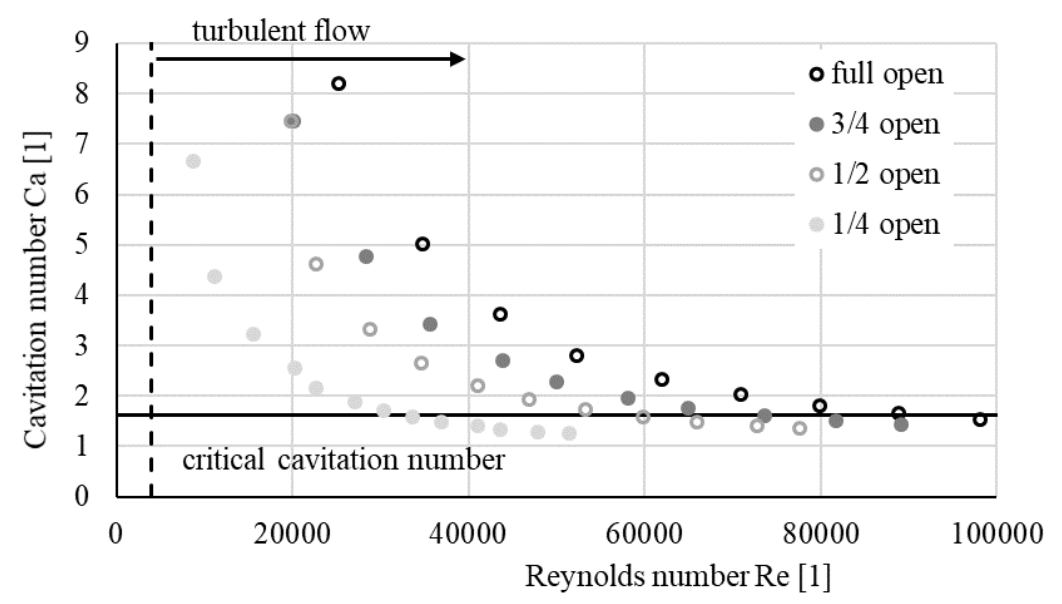

Fig. 6. Dependence of cavitation number vs Reynolds number.

\section{Conclusion}

From the results in the article it is clear that:

- a methodology for measuring the static characteristics of valves on water and air was compiled, the valve was measured in four positions.

- measurements for air can be evaluated as incompressible for a given experiment, as the Mach number is very low (on the order of $10^{-3}$ to $10^{-2}$ ).

- the critical Reynolds number for the transition from laminarity to turbulence for valves is 4000 and turbulent flow was achieved in both cases.

- dependence of flow coefficient $K v$ vs. $R e$, resp. loss coefficient $\xi$ vs. Re are characterized by a common feature, i.e. at higher Reynolds numbers they are constant (Figure 4).

- from the evaluation of the loss coefficient it can be seen that the smaller the flow area through the valve, the larger the loss coefficient (Figure 5).

- with the valve open, the water loss coefficient is $11.5 \%$ higher than the air loss coefficient.

- a critical cavitation number for water has been determined. For higher Reynolds numbers and larger valve openings, cavitation is almost non-existent, whereas for $1 / 4$ openings, cavitation was very clearly audible.

In the future, the work will be used for mathematical modelling of fluid flow in valves (see lit. [8]), where it is easier to model a variant of compressible gases (air, a mixture of air and vapour). The measurement methodology will be used for other valve diameters and strokes. The experiment can be used for more accurate identification of cavitation on valves, i.e. for measuring noise or vibration.

In technical practice, vapour plays an important role, but in laboratory conditions to create a source of vapour with sufficient flow is energy intensive. It will then be possible to use 
conclusions and experience with mathematical modelling (water and air flow) to determine the resistance coefficients of vapour.

Acknowledgments

This paper has been done in connection with project FV40115 Development of a new series of medium-pressure valves, their manufacturing technology and testing methodology, simulating 60 years of service life.

The work presented in this paper was supported by a grant SGS „,Research in the field of energysaving device for testing rotary hydraulic motors." SP2020/25.

\section{References}

1. J. Roček Prưmyslové armatury. Praha: Nakladatelství Informátorku, spol. s.r.o. 204s. (2002)

2. Kol. autorů: Regulačni armatury 4. vydání, LDM, spol s.r.o., 166s. (2006)

3. ČSN EN 60534-2-3 (134523) Regulační armatury pro průmyslové procesy - Část 2-3: Průtok - Zkušebni postupy. Účinnost od 01/2000

4. ČSN EN 1267 Průmyslové armatury - Měření průtokových ztrát s použitím vody jako zkušební tekutiny. Účinnost od 08/2012

5. J. Noskievič, Kavitace v hydraulických strojich. Praha (1989)

6. K. Ražnjevič Termodynamické tabulky. Bratislava (1984)

7. B. Glück, N. Heizwasser Verlag für Bauwesen. Berlin (1985)

8. T. Polášek, A. Bureček L. Hružík Mathematical simulation of temperature influence on pressure drop at pump suction line. EPJ Web of Conferences [online]. 213. (2019) DOI: 10.1051/epjconf/201921302069

9. J. Jablonská, M. Kozubková, Flow characteristics of control valve for different strokes. EPJ Web of Conferences, 114. (2016) DOI: 10.1051/epjconf/201611402049

10. W. Sutherland, The viscosity of gases and molecular force. Philosophical Magazine. s. 5, 36 pp. 507-531. Dostuné z https://www.cfd-online.com/Wiki/Sutherland\%27s law

11. Ansys 19 R3, Fluent 19 R3, https://ansyshelp.ansys.com/ 